\title{
Research on the Present Situation of Piano Education in Colleges and Universities
}

\author{
Zhenyu Hu \\ Conservatory of Music, Nanyang Institute of Technology, Nanyang, China \\ Corresponding author e-mail: nylghu@163.com
}

Keywords: Music education, Piano teaching, Teaching method

\begin{abstract}
To propose some reasonable and scientific teaching methods for piano teaching, the piano teaching of music education majors in comprehensive art colleges was studied. Literature search methods, comparative analysis methods, observation methods, survey methods, and field survey methods were used to study piano teaching. First, the status quo and characteristics of piano teaching were discussed. Second, the way of piano teaching reform was discussed. Third, several suggestions were proposed to improve piano teaching. Finally, the significance of improving the level of piano teaching and the problems to be solved were discussed. The results showed that the appropriate music teaching method improved the professional quality and innovative spirit of students. In summary, teachers of music education can cultivate students' passion for music through the practical experience of piano teaching.
\end{abstract}

\section{Introduction}

The piano course is a compulsory course for music education majors in comprehensive art colleges. Nowadays, music education has established piano performances, piano teaching materials, piano history of Chinese and foreign music, and impromptu accompaniment. The piano is the most widely used in the teaching work of students in the future. Therefore, piano education occupies an important position in the music education major of the comprehensive art school. The reform and research of piano teaching in comprehensive art colleges has been further deepened [1].

The training objectives of music education majors in comprehensive art colleges are very clear. Through the practical experience of piano teaching and teaching, students' enthusiasm for music education is stimulated. The professionalism and teaching ability of the students are improved. In the future teaching process, the spirit of innovation is emphasized. Students should have the basics of music theory and practical experience in teaching in primary and secondary schools or in separate pianos, so as to train qualified music teachers for primary and secondary schools [2].

\section{State of the Art}

The drawbacks of traditional music teaching are discussed. Yucetoker elaborates on the characteristics of the new music curriculum in China. Based on the theory of constructivism, its guiding significance in music teaching is studied. Teachers, students, and teaching models were analysed [3].

Demirci puts forward the prospect of constructivist theory and the specific guiding role of this learning theory in the whole piano teaching process. Combined with the current practice in music education and teaching and based on constructivism, the innovation of music education development is explored [4].

Toptas explains the importance of music textbooks in music teaching. It further embodies the practical significance and core ideas of modern music education [5].

Baker summarizes the philosophical views on the theory of "constructivism." He first mentioned the stage of the developmental experience of constructivism, and then summarized and studied the research methods. The music teaching in colleges and universities is mainly summarized. Proposals 
for the application of constructivism were proposed. Its practical significance is pointed out [6].

\section{Improvement of Piano Teaching Level}

\subsection{Suitable Teaching Materials}

For the teaching model, 200 college piano students were investigated. The result is shown in Figure 1, Figure 2 and Figure 3:

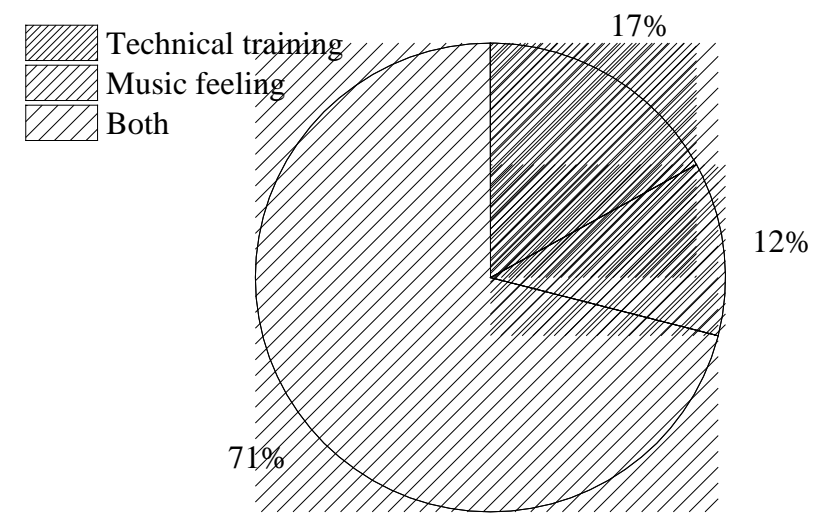

Figure 1 Focus in piano teaching

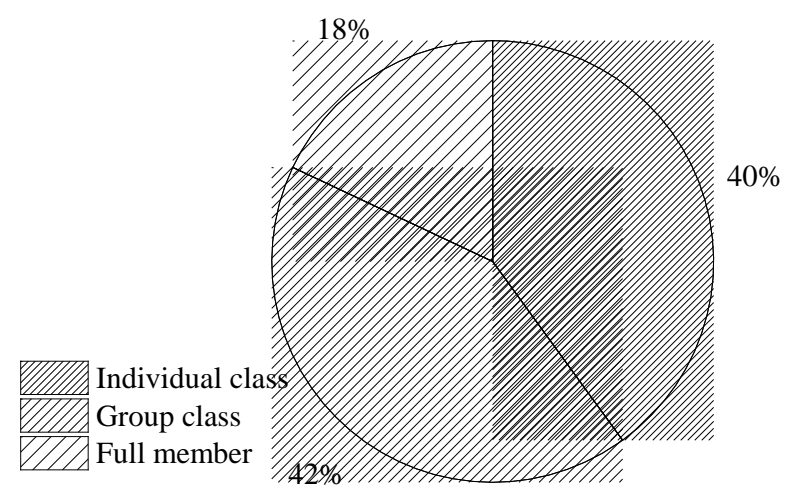

Figure 2 Investigation on the pattern of piano lessons during the school

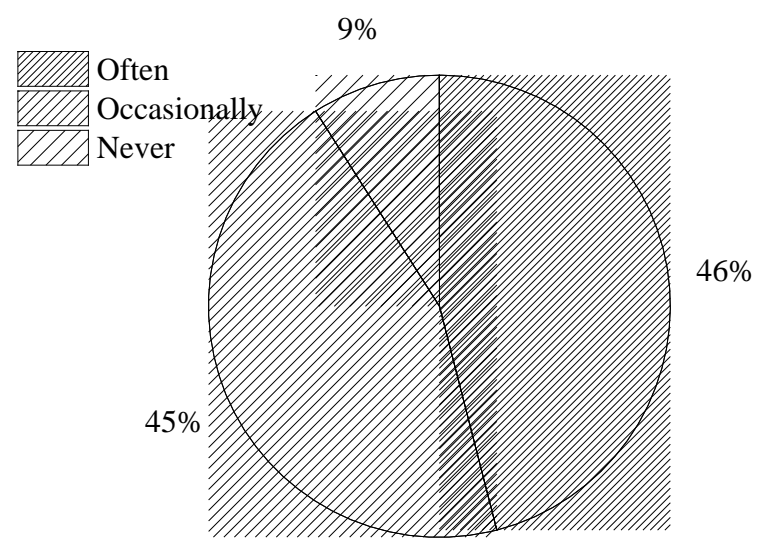

Figure 3 Academic exchange activities of students at school

Different types of textbooks allow students to experience different styles of work. The art history of piano has a long history. It is not only classical or romantic. The frog at the bottom of the well will not know the wonderful world outside. Therefore, in teaching, the teaching materials should be broad. From Baroque to modern, skillful exercises, twelve tone equal temperament, and various sonatas and music are known. Students should learn a variety of styles. In this way, students can 
absorb more nutrients and their horizons can be broadened. Teachers' guidance to students is important. Choosing good teaching materials is the focus of modern piano teaching and one of the standards for measuring teaching level. This helps to improve students' skills and master the musical style.

\subsection{Cultivation of National Music}

Ethnic music is an important part of Chinese culture. Piano teaching in comprehensive art colleges should strengthen the cultivation of students' national music education. However, most of today's piano teachers are influenced by Western musical concepts, which has led to the inadequacy of traditional Chinese folk music to students. Therefore, it is necessary to increase Chinese piano works for teaching.

The creation and aesthetics of Chinese piano music works have their unique humanistic significance. China has attached importance to the harmony of nature and humanity since ancient times. Western piano art has naturally been influenced by traditional culture after entering China. Piano works is created with Chinese characteristics. With the progress of Chinese society, piano music is also developing rapidly. At the same time, traditional music culture should be promoted. In the development of world piano music, national culture is valued. Music with national characteristics should be integrated into the world music. Piano teachers in integrated art colleges have the responsibility to expose students to Chinese piano music and let them feel the charm of Chinese piano music. At present, the cultivation of ethnic music is one of the problems to be solved.

\subsection{Unique Music Performance Style}

In the piano teaching of comprehensive art colleges, students should learn to think independently and have their own judgment in doing things. Piano teachers should let students have their own initiative. When playing some piano works, they can use their own imagination to express their own opinions. Students should actively communicate with teachers, which will help to improve the performance of piano works. In addition to mastering the basic principles, students should make full use of their own characteristics and personality, so that the music works can be more expressive and the music is full of vitality. Therefore, students should have unique insights and appropriate use of their imagination to show their personality and talent. Musical works are innovated to have a unique playing style. In this way, students will highlight themselves in their future studies.

\subsection{Improvement of the Quality of Teachers}

Based on improving the level of piano teaching, the quality of teachers has been comprehensively improved. Piano teachers must constantly enrich themselves. In addition to mastering the skills of piano playing, teachers must have the ability to pass on these skills to students. Piano teachers should constantly absorb some of the most cutting-edge knowledge to enrich themselves, so that students can learn knowledge in the first place. Piano teachers also need to apply the knowledge of psychology to understand the psychological characteristics of students and help students to complete their studies. In short, the level of piano teaching in music education in comprehensive art colleges plays a vital role in improving the overall quality of contemporary college students. Only when the quality of teachers is improved, the level of teaching will be greatly improved. Excellent artistic talents are cultivated.

\section{Suggestions on Piano Teaching Reform}

\subsection{The Richness of Piano Teachers' Classroom Language Art}

To improve the quality of piano teaching, the quality of teachers themselves is very important. The communicator of culture is a teacher. Music is an artistic expression. Therefore, for music teachers, it is a communicator of culture and art. The movement of language is particularly important. For the entire piano teaching process, piano teachers must pay attention to the rational use of language. Especially during piano teaching, the beauty of language and the beauty of art are perfectly combined. Students feel the charm of art in the piano class. Students are integrated into the 
music to truly enjoy the infinite artistic charm of music.

\subsection{Improvement of Students' Professional Skills}

To improve the quality of piano teaching in comprehensive art colleges, teachers must have a good teaching language, professional ability and emotional education. This is one of the important teaching goals of improving the teaching level of piano and cultivating students.

For example, "Chopin Etudes Lesson 1", C major, and skillful vocal exercises are a good example of the students' piano skills. When the arpeggio is running, the strength of the wrist should be mastered, and the melody of the music will not be confused. If the students do not lay the foundation, such a skillful Etude is difficult to complete in the future exercises. Therefore, to do basic training, students should take gamut, semi-gamut and arpeggio as the primary training program for the usual practice. The training and practice of gamut, semi-gamut, arpeggio etc, play an important part in piano teaching.

In the piano teaching of music education majors in comprehensive art colleges, heuristic teaching principles should be applied. Music teachers must be rigorous and flexible. By letting students know about new works, students' musical perceptions are improved. Music teachers constantly train and guide students. While gradually solving the technical and musical content, students can grasp the playing style of the piano works. The student's emotions are expressed through the perception of music.

\subsection{Emphasis on Practical Teaching}

For the practice of piano performance, 200 college piano students were investigated. The results are shown in Figure 4, Figure 5 and Figure 6:

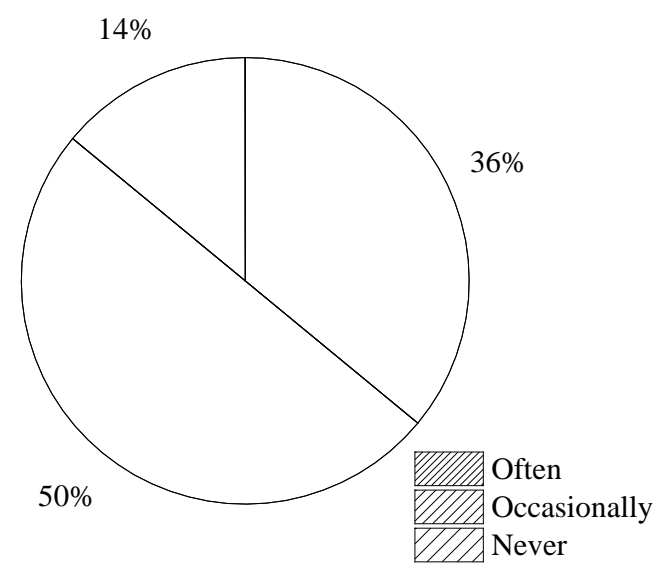

Figure 4 Survey of opportunities for students to perform on stage (or competition) during school

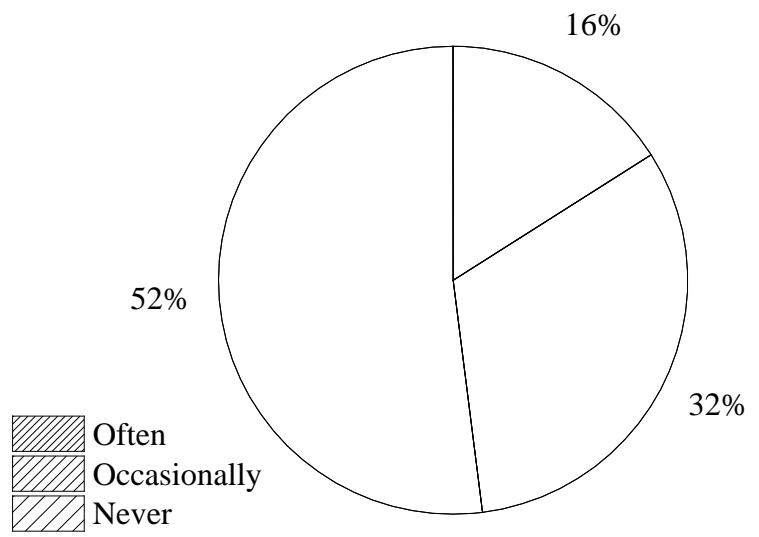

Figure 5 Survey of opportunities for off-campus counseling during school 


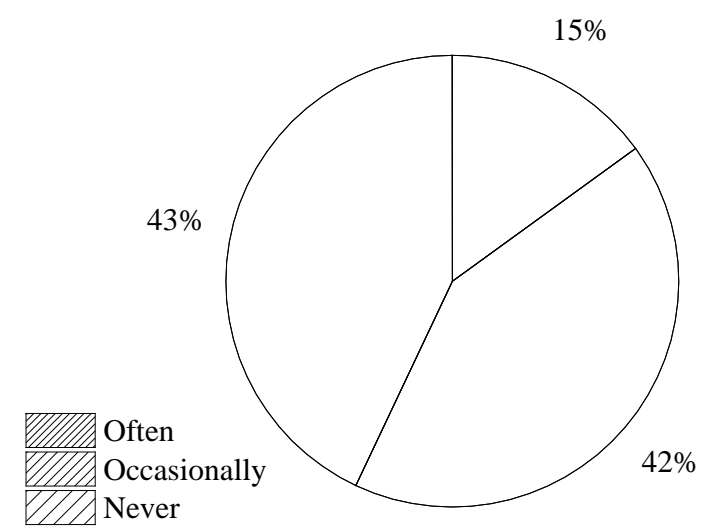

Figure 6 Investigation of opportunities for other instrumental or vocal accompaniment

From the above survey results, it can be seen that during the period of piano students in colleges and universities, there is still much room for improvement in piano practice opportunities. Art practice is very important for students majoring in piano education at the college of art. The school trains students in education, that is, to train outstanding music teachers in the future. Therefore, during the school, the teacher is not only to train the students' professional skills, but also to provide students with the corresponding professional qualities and teaching ability. Through the observation of the students of piano education in an art school, the students' language organization ability is not very good, the innovation in the classroom is not enough, and the teaching practice experience and technology are lacking. In this way, in the absence of professional literacy, the students of the piano education major are qualified for the post-graduation teaching work and complete the role change in the teaching process. Now, the piano teaching in the comprehensive art school has a new thinking. The training of qualified music teachers and outstanding artistic talents are emphasized. Students in piano education must pay attention to practice and teaching internships.

\subsection{Cultivation of Creative Ability and Perception Ability}

The educational concept of society is constantly improving, and the pace of education is also advancing with the times. People pay more attention to the innovative thinking that piano education brings to students. In the music teaching of comprehensive art colleges, students' innovative thinking is cultivated. Students fully master the knowledge of music theory and improve their curiosity. Students gradually form a divergent thinking. Piano teaching has practical significance in cultivating students' innovative ability.

In fact, when students go to school, teachers begin to emphasize that music is a very important part of the development of morality, intelligence, and beauty. It is also an important criterion for evaluating a person. Therefore, the piano education of music education in comprehensive art colleges has been given important practical significance. Piano education not only enhances students' appreciation, but also helps to form a healthy human character. If the teacher can stimulate the students' ability to innovate and perceive, the students will correctly understand the life of sentiment. Piano teaching in comprehensive art colleges is extremely important to motivate college students to have innovative capabilities.

\section{Conclusion}

As a piano teacher in a comprehensive art school, education must be the fundamental goal. The curriculum, management system, teaching content, teaching methods and teaching materials were comprehensively reformed. The traditional music teaching model was improved. A complete education system was established in reform and innovation. Students not only have excellent piano performance, but also master music theory and teaching skills. The overall quality of the students is improved. They can become a qualified music teacher after graduation. The current state of piano teaching is analysed. By reforming the methods and means of piano teaching, students' musical literacy is improved. In response to the problems of traditional teaching methods, some 
corresponding measures are proposed. The academic value of this research lies in improving the shortcomings of traditional music teaching methods. Due to limited time and energy, this study has many shortcomings. In the future, this topic will be explored in depth.

\section{References}

[1] Blacker, S., Head, B. A., Jones, B. L., Remke, S. S., \& Supiano, K. (2016). Advancing hospice and palliative care social work leadership in interprofessional education and practice. Journal of social work in end-of-life \& palliative care, 12(4), 316-330.

[2] Li, R., Wang, Y., Davis, N., Hallam, J., \& Do, E. (2016). Tactile teacher: enhancing traditional piano lessons with tactile instructions. 329-332.

[3] Yucetoker, I. (2016). The visual memory-based memorization techniques in piano education. Eurasian Journal of Educational Research, 2016(65), 111-128.

[4] Demirci, S. A. (2016). Arranged bursa folk songs for fourhands piano and their practice in music education departments. Educational Research \& Reviews, 11(21), 1986-2001.

[5] Toptas, B. (2016). Effect of daily work on student's memorization ability in piano education. Educational Research \& Reviews, 11(7), 371-376.

[6] Baker, V. A. (2017). Teachers' perceptions on current piano use in the elementary general music classroom. Update Applications of Research in Music Education, 35(2). 